\title{
TITLE: EFFECT OF REPEATED ALVEOLAR RECRUITMENT MANOEUVRE ON OXYGENATION AFTER CARDIAC SURGERY
}

AUTHORS: Leonid Minkovich, MD, George Djaiani, MD, Rita Katznelson MD, Fergal Day MD, Jo Carroll RN, Jens Tan MD, Jacek Karski MD

AFFILIATION: Department of Anesthesia \& Pain Management, Toronto General Hospital, University Health Network, University of Toronto, 200 Elizabeth Street, Toronto, ON, Canada M5G 2C4

BACKGROUND: Atelectasis formation and impairment in oxygenation remains a common, clinically significant problem after cardiac surgery. Lung recruitment maneuver has been shown to abolish atelectasis in a pig model. We conducted a randomized, control trial to determine the impact of repeated lung recruitment maneuver on arterial oxygenation of patients after cardiac surgery.

METHODS: After REB approval 95 patients undergoing elective cardiac surgery with tepid CPB were randomly allocated to receive conventional management (control) or repeated Vital Capacity Maneuver (VCM group). In the VCM group sustained lung inflation to $35 \mathrm{~cm} \mathrm{H} 2 \mathrm{O}$ for $15 \mathrm{sec}$ was done immediately prior to separation from CPB and secondary $(30 \mathrm{~cm} \mathrm{H} 2 \mathrm{O}$ for $5 \mathrm{sec})$ after ICU admission. Th efirst clinica lend point was the $\mathrm{PaO}_{2} / \mathrm{FiO}_{2}$ ratio as a parameter allowing for comparison of oxygenation between patients with wide range of $\mathrm{FiO}_{2}$. It was measured at predetermined time points: after induction of anesthesia, 15 min after separation from CPB, at ICU admission, after three hours of positive pressure ventilation (PPV), after extubation of trachea, and just before ICU discharge. Th esecond clinica lend point was duration of mechanical ventilation, ICU and hospital length of stay (LOS).

RESULTS: Both groups were comparable with respect to demographic data, and surgical characteristics. There were no adverse events related to the VCM application.

The main finding of this study is that repea ed VCM resulted in better arterial oxygenation extending from immediate postoperative period to approximately 24 after surgery, at the time of ICU discharge (Fig1). Furthermore, application of repea ed VCM was associated with shorter ICU LOS.

Figure 1. Comparison of $\mathrm{PaO}_{2} / \mathrm{FiO}_{2}$ ratio between the VCM and control groups.

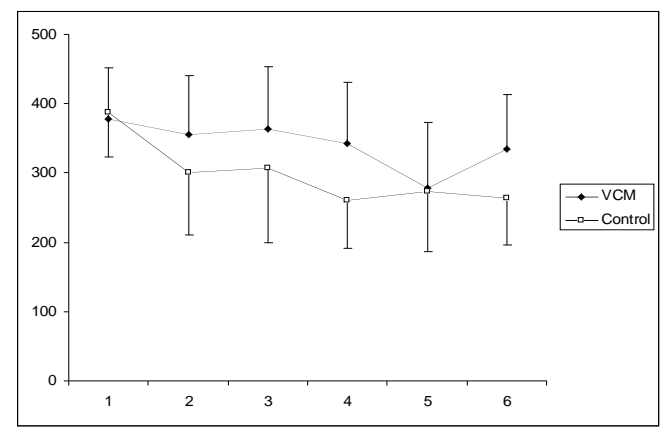

Measurements were taken at predetermined time points:

1. OR post tracheal intubation

2. 10-15 minutes after separation from $\mathrm{CPB}$

3. $15 \mathrm{~min}$ after arrival in ICU

4. 3-hours after ICU admission

5. 30 minutes after tracheal extubation

6. Immediately prior to ICU discharge

$* \mathrm{p}<0.01 ; * * \mathrm{p} \varangle 0.05$

CONCLUSION: Repeated VCM appears to be effective method to preserve lung oxygenation after cardiac surgery with CPB. 